\title{
Eksistensi LPP TVRI Dalam Industri Penyiaran
}

\author{
Junaidi Diharyo, Wulan Purnama Sari \\ Junaidi.diharyo@yahoo.com,wulanp@fikom.untar.ac.id
}

Fakultas Ilmu Komunikasi Universitas Tarumanagara

\begin{abstract}
Abstrac
This study discusses the existence of LPP TVRI in the broadcasting industry. The purpose of this study is to find out how TVRI has survived in the TV industry to date. This study uses qualitative research methods with descriptive analysis in which the method uses case studies as the main foundation for finding data. Data collection techniques that have been used by the author are interviews, direct observation on TVRI to find out how to know how TVRI to deal with these problems. The results of this study are to describe how the broadcast industry in TVRI and also to know the situation of TVRI in the present era This has been abandoned by many people because the shows have not followed the current trends and programs that TVRI currently shows has changed in terms of content - the program content has begun to be modern, not only in terms of broadcasting programs the event but TVRI also advertises various products or services belonging to other companies / clients,
\end{abstract}

Keywords: TVRI, TV Industry, Broadcasting Industry.

\begin{abstract}
Abstrak
Penelitian ini membahas tentang Eksistensi LPP TVRI dalam industri penyiaran. Tujuan penelitian ini adalah untuk mengetahui bagaimana cara TVRI bertahan di industri TV hingga saat ini. Penelitian ini menggunakan metode penelitian kualitatif dengan analisis deskriptif yang dimana dalam metode tersebut menggunakan studi kasus sebagai landasan utama untuk mencari data. Teknik pengumpulan data yang telah digunakan oleh penulis adalah wawancara, observasi langsung di TVRI untuk mengetahui bagaimana cara mengetahui bagaimana cara TVRI untuk menghadapi masalah tersebut.hasil dari penelitian ini adalah untuk menggambarkan bagaimana industri penyiaran di TVRI dan juga untuk mengetahui bagaimana situasi TVRI di era sekarang ini yang sudah banyak ditinggalkan oleh masyarakat karena tayangan - tayangannya sudah tidak mengikuti trend perkembangan jaman yang ada dan juga program - program acara yang TVRI tayangkan saat ini sudah mengalami perubahan dari segi konten - konten acaranya yang sudah mulai modern, tidak hanya dari segi penyiaran program acara tetapi TVRI juga mengiklankan berbagai produk atau jasa milik perusahaan perusahaan lainnya / klien,
\end{abstract}

Kata kunci : TVRI, industri TV, industri penyiaran

\section{Pendahuluan}

Stasiun TV yang ada di Indonesia cukup banyak dan juga sangat beragam, berbagai macam informasi maupun hiburan akan diberikan kepada masyarakat yang sedang menonton TV. Berbagai tayangan TV yang diberikan kepada masyarakat berupa komedi, musik, drama sampai berita tentang politik juga diberikan agar masyarakat bisa memilih dengan baik acara maupun tayangan yang mereka inginkan. Terjadinya persaingan antara stasiun TV satu dengan yang lainnya membuat beberapa stasiun TV lain jadi kurang diminati.

Kurangnya minat penonton berpengaruh pada rating dan TV share, padahal banyak biaya yang dihabiskan untuk membuat sebuah acara maupun tayangan. Jika acara maupun tayangan tersebut tidak banyak menghasilkan penonton maka stasiun 
TV tersebut akan mengalami kerugian dan berujung pada hal yang sangat fatal yaitu mengalami kebangkrutan dan tidak akan beroperasi kembali di industri TV (Dewi, Santi 2018).

Menurut Kominfo (2013). Stasiun TV dibagi menjadi 2, swasta dengan pemerintah. Swasta seperti RCTI, Trans TV, Net dan masih banyak stasiun TV Swasta lainnya. Kemudian terdapat juga TV Lokal milik negara yang semua pengeluaran untuk produksi acara maupun tayangan ditanggung oleh negara, stasiun TV yang sudah berjalan sejak tahun 1962 yaitu TVRI (Televisi Republik Indonesia), stasiun TV ini dikenal dengan Tagline "Media Pemersatu Bangsa". Nama TVRI sendiri bisa dibilang cukup besar di Indonesia, stasiun ini juga menyiarkan berbagai acara di dalamnya dan juga menerima jasa untuk menyiarkan iklan - iklan yang masuk untuk disiarkan di TVRI.

Berdasarkan latar belakang masalah penelitian tersebut, munculnya rumusan masalah yang nantinya akan diselesaikan dan juga akan dapat dicari jawabannya, rumusan masalah dalam penelitian ini adalah bagaimana cara TVRI masih bisa eksis mengingat sudah banyak TV swasta yang sudah mengambil alih industri TV dan mengapa TVRI masih ingin menunjukan kualitasnya di tengah ketatnya persaingan tersebut, merupakan hal positif yang dilakukan TVRI karena masih terus eksis hingga sekarang dan TVRI sendiri tidak ingin masyarakat terus melupakan TVRI dan ingin masyarakat menonton kembali tayangan - tayangan yang diberikan TVRI kepada masyarakat.

Tujuan dari TVRI yaitu untuk mengetahui dan juga menggambarkan bagaimana cara TVRI masih terus bisa eksis dalam industri penyiaran. Penting sekali bagi TVRI untuk terus menyiarkan program - program yang sejati nya sudah tidak mengikuti perkembangan jaman yang ada, membosankan bagi kaum milenial karena konten yang ada di tayangan TVRI berbaur tentang budaya, Pendidikan, dan juga entertaint. Mengingat TV swasta yang sudah mengambil era keemasan TVRI yang pada waktu itu tahun 1968 - 1990 an TVRI sangat menguasai sekali dunia TV karena belum masuknya TV swasta di Indonesia. Penelitian ini berfokus pada keberadaan TVRI sebagai satu-satunya stasiun TV milik negara tetapi justru secara rating dan TV share rendah. Penelitian ini mengkaji tentang penyebab dari hal tersebut dan tentang bagaimana cara TVRI dalam bertahan di industri TV (Beranda TVRI).

\section{Metode Penelitian}

Metode yang digunakan dalam penelitian ini adalah pendekatan kualitatif, dengan tujuan untuk mengetahui bagaimana cara TVRI bertahan dalam industri TV. Penelitian kualitatif adalah keterkaitan spesifik pada studi hubungan sosial yang berhubungan dengan fakta dari pluralisasi dunia kehidupan.

Melalui stasiun nasional pemasang iklan dapat menyiarkan pesan iklannya ke hampir seluruh wilayah negara secara serentak. Salah satu keuntungan memasang iklan di stasiun nasional adalah kemudahan dalam proses pembelian waktu siaran iklan. Pemasang iklan hanya berurusan dengan satu pihak saja, yaitu stasiun TV dan radio atau perwakilannya. Pemasang iklan yang tertarik untuk menjangkau sebagaian besar khusus yalak di seluruh negeri dapat menggunakan stasiun penyiaran nasional (Morissan, 2010).

Menurut Yin (2013) Metode ini diterapkan untuk melihat dan memahami subjek dan objek penelitian yang meliputi orang, lembaga berdasarkan fakta yang tampil secara apa adanya. Melalui pendekatan ini akan terungkap gambaran mengenai 
aktualisasi, realitas sosial, dan persepsi sasaran penelitian. Penelitian kualitatif dimaksudkan untuk memahami perilaku manusia, dari kerangka, bagaimana pelaku memandang dan menafsirkan kegiatan dari segi pendiriannya. Peneliti dalam hal ini berusaha memahami dan menggambarkan apa yang dipahami dan digambarkan subjek penelitian. Untuk maksud tersebut, peneliti menggunakan pendekatan kualitatif. Disebut kualitatif karena sifat data yang dikumpulkannya bercorak kualitatif bukan kuantitatif yang menggunakan alat-alat pengukur.

Subjek dari penelitian ini adalah Subjek penelitian, adalah tempat, orang dan benda yang diamati dalam rangka penelitian tentang bagaimana cara TVRI masih bisa eksis hingga sekarang ini. Dalam penelitian ini, subjek penelitiannya adalah kesiapan TVRI dalam menangani berbagai masalah dan juga bagaimana TVRI bisa bertahan hingga sekarang.dalam industri penyiaran. Dan juga Objeknya adalah Hal yang menjadi objek penelitian ini adalah TVRI sebagai salah satu stasiun TV milik negara yang masih eksis dalam industri penyiaran hingga sekarang.

\section{Hasil Penelitian}

Mulai dari divisi Account Executive, divisi ini menjadikan klien sebagai prioritas utama dalam proses kerjanya. Dikarenakan sebagai bentuk apresiasi karena telah bekerja sama dengan TVRI sekaligus membuat TVRI mempunyai pemasukan, Mulai dari jasa penayangan sampai bagian produksi iklan maupun film. Itu semua merupakan hal yang pasti di dapat ketika klien telah sepakat untuk bekerjasama dengan TVRI sebagai media untuk menayangkan produk mereka dan sekaligus memperkenalkan kepada masyarakat apa itu produk yang dijual.

Account Executive di TVRI merupakan bagian yang khusus untuk menangani klien dan juga mencari klien baru yang tentunya akan membuat TVRI lebih mempunyai banyak pemasukan untuk perusahaannya dan juga akan membuat TVRI lebih banyak diketahui lagi oleh banyak perusahaan agar nantinya banyak perusahaan akan lebih percaya lagi jika ingin bekerja sama dengan TVRI.

Era pertama kehadiran TVRI, juga dimaknai sebagai Era Keemasan. Di bawah payung kebijakan penyiaran monopolistik, dalam paruh kedua, program berita dikemas dengan format "menurut petunjuk Bapak Presiden." TVRI menjadi media tunggal penyiaran televisi pemerintah yang beroperasi ke seluruh Indonesia. Sejak berstatus Yayasan TVRI, hingga sebagai Unit Pelaksana Teknis Penyiaran Televisi di bawah Departemen Penerangan, diterapkan kebijakan diseminasi informasi model "top down". Dengan memanfaatkan teknologi penyiaran televisi analog melalui hibah peralatan luar negeri, para kru TVRI mampu menyajikan program nonberita dengan prima. Terlebih didukung kekayaan seni budaya, diversitas etnis dan sosial sebagai sumber inspirasi, maka hal itu menjadi kunci sukses program.

Tahun ini, TVRI membuat sebuah kemajuan dimulai dari dibentuknya divisi media sosial TVRI yang pastinya akan memberikan pengaruh positif kepada masyarakat, pastinya setiap program - program acara yang di berikan TVRI telah berubah menjadi salah satu stasiun TV yang tidak kalah baiknya dengan stasiun TV lain dan terlebih lagi acara - acara yang tetap mendidik tetapi tidak memecah belah persatuan bangsa Indonesia.

Dalam penelitiannya, penulis sering kali diajak untuk bertemu dengan klien dan menyaksikan langsung bagaimana cara untuk berbicara dengan klien dan juga mengamati apa yang klien mau dan juga mencari tau jenis iklan apakah yang klien inginkan untuk iklan yang diajukan. Menarik, karena setiap klien mempunyai karakter 
yang berbeda dan mempunyai keinginan yang berbeda untuk setiap jenis iklan apa yang ingin digunakan untuk produk atau jasanya.

Klien akan senang ketika TVRI menuruti apa yang mereka inginkan, tetapi jika berlainan dengan apa yang inginkan, maka secara tidak langsung klien akan menolaknya dan segera lekas pergi dan tidak berminat lagi bekerja sama dengan TVRI. Berbeda tanggapan, mulai dari mahalnya harga, tidak turunnya harga, sampai cara persentasi dari pihak Account Executive yang kurang baik bisa menjadi faktor perginya klien yang akan baru mulai bekerja sama dengan TVRI. Maka dari itu, sangat penting jika para Account Executive memberikan materi yang tidak membosankan, memberikan yang terbaik untuk klien sampai memanfaatkan situasi yang terbaik agar klien mau bekerja sama dengan TVRI.

Tabel 1. Daftar Klien yang bekerjasama dengan TVRI

\begin{tabular}{|cc}
\hline No & Daftar Klien TVRI \\
\hline 1. & PT. Djarum \\
2. & PT. Global Digital Niaga (Blibli) \\
3. & PT. Victoria Care \\
4. & SKK MIGAS \\
5. & PT. Polytron \\
6. & Mahkamah Konstitusi \\
\hline
\end{tabular}

Sumber : Dokumentasi Peneliti (2019)

Seringkali klien menanyakan tentang keuntungan apa saja yang di dapat ketika bekerja sama dengan TVRI, pihak Account Executive menjawab jika klien bersedia bekerja sama dengan TVRI maka keuntungan yang di dapat ialah harga. Harga yang murah menjadikan TVRI tempat yang sering di tanyakan masyarakat, munculnya ketertarikan dari klien yang membuat mereka ingin bekerja sama dengan TVRI. Keinginan dari klien bermacam - macam sehingga seorang Account Executive bekerja keras memperkenalkan apa yang ditawarkan oleh TVRI mulai dari materi yang akan disampaikan, entah itu proses penayangannya sampai jadwal produksi.

Klien bekerja sama dengan TVRI itu merupakan langkah awal bagi TVRI untuk memajukan kesejahteraan TVRI dan juga memotivasi pihak TVRI agar dapat berkembang lagi kedepannya dan membuat program - program yang pasti lebih mengedukasi masyarakat dan juga dapat menyatukan lagi masyarakat Indonesia dengan menonton film maupun tayangan di TVRI.

Banyak acara TVRI yang sebenarnya merupakan acara yang tidak kalah seru dibandingkan stasiun TV lain, di mana stasiun TV lain menayangkan kurang mendidik dan juga sedikit sekali menambah wawasan masyarakat dikarenakan apa yang ditampilkan sedikit sekali mempunyai nilai sekaligus arti dalam apa yang dipertontonkan. Banyak acara menarik yang ditayangkan TVRI kepada masyarakat agar bisa menambah wawasan masyarakat tentang apa yang ditonton di TVRI, program - program yang ditawarkan oleh TVRI tidak memecah belah masyarakat Indonesia sebaliknya, apa yang disiarkan oleh TVRI sangat memberikan nilai - nilai yang sangat tinggi bagi siapapun yang menontonnya.

Contohnya acara "Salam Olahraga", di acara tersebut membahasa berbagai macam cabang olahraga yang di mana TVRI membuat program acara tentang 
olahraga, berita - berita terbaru tentang cabang olahraga apa yang sedang berlangsung baik itu cuplikan tentang sepak bola sampai berita tentang cabang olahraga silat di sajikan untuk masyarakat Indonesia dan juga acara "Indonesia Hari Ini", yang menyiarkan berbagai peristiwa yang sedang terjadi maupun berita tentang politik.

Banyaknya program acara - acara yang dikeluarkan dari stasiun TV lain untuk menarik perhatian masyarakat agar masyarakat memilih stasiun TV mereka untuk menjadi sarana hiburannya tetapi tidak kalah dengan TVRI. Walau merupakan stasiun TV yang sudah berdiri sejak tahun 60-an, tetapi TVRI terus memberikan program program acara yang mengikuti era sekarang.

Berbagai macam program acara yang dikeluarkan TVRI salah satunya adalah acara pendidikan, banyaknya anak - anak milenial sekarang yang tidak begitu menyukai membaca buku ataupun koran, mereka lebih senang untuk menonton TV atau memainkan media sosial mereka maka itu TVRI memberikan sarana pendidikan kepada masyarakat agar masyarakat bisa mengetahui hal banyak tentang kejadian apa yang terjadi di seluruh dunia, hal-hal sejarah yang tidak pernah diketahui, dan sebagainya. Masih banyak lagi, acara - acara yang ditawarkan oleh TVRI yang pastinya akan membuat masyarakat menyukai dan mendukung TVRI untuk berkembang lebih jauh lagi di dunia TV. Contohnya acara "Indonesia Hari Ini”, yang setiap harinya memberikan informasi yang tepat dan juga menarik agar masyarakat bisa mengetahui tentang apa saja yang terjadi hari ini.

Mulai dari hiburan yang tentunya mengandung unsur humor sekaligus akan membawakan tawa bagi siapapun yang menontonnya dan masih banyak lagi sebenarnya acara yang TVRI sajikan di antaranya seperti berita olahraga, berita terbaru seputar sepak bola, bulu tangkis, basket, angkat beban, dan masih banyak macam lagi cabang olahraga lainnya yang disiarkan oleh TVRI dan juga tidak kalah menarik dari berbagai macam acara yang ditayangkan ada salah satu program acara menarik yang dimana stasiun TV lain masih kurang mengangkat tema tentang kebudayaan Indonesia.

Lain halnya di TVRI, dari awal masa kejayaan TVRI dari dulu sampai sekarang, TVRI sama sekali hampir tidak mengubah tema program acara yang ditayangkan terkait dengan beragam - ragam budaya yang ada di Indonesia. Menjadi keuntungan tersendiri bagi TVRI di karenakan program acara tentang budaya sangat memotivasi agar mempersatukan bangsa Indonesia karena Indonesia memiliki berbagai macam budaya yang berbeda dan mempunyai banyak sekali adat - adat maupun suku yang berbeda semua dibahas di program acara TVRI bertemakan budaya.

Sangat menarik sekali tentang apa yang diberikan oleh TVRI kepada masyarakat Indonesia dengan memberikan acara - acara menarik sekaligus mendidik dan tidak memecah belah bangsa Indonesia sekaligus membanggakan TVRI sebagai media pemersatu bangsa yang pastinya semua yang TVRI berikan itu semua dapat memberikan nilai - nilai yang positif tanpa adanya konflik sekalipun.

Dalam dunia TV, terkadang pasti terjadi penurunan jumlah penonton dan mungkin hampir tidak ada sama sekali yang menonton hanya ada beberapa penonton saja yang tertarik menonton program - program acara di TVRI. Biasanya masyarakat cenderung menonton acara - acara yang menurut mereka mengandung unsur humor dan yang terpenting acara yang di tayangkan mengikuti tren jaman saat ini.

Meskipun sekarang sudah banyak acara - acara TV yang sudah mengikuti tren jaman yang ada saat ini mengakibatkan TVRI semakin berusaha untuk membuat masyarakat lebih percaya lagi dengan apa yang TVRI tawarkan. disebabkan karena program - program acara yang disiarkan di TVRI hanya sebatas itu saja atau bisa 
dibilang tidak mengikuti tren di dunia TV saat ini. Hal tersebut yang membuat nama TVRI sudah mulai dilupakan oleh masyarakat Indonesia terlebih lagi khususnya anak - anak muda saat ini yang cenderung menonton acara tren jaman saat ini. Kemudian jika dilihat dari segi jumlah penonton TVRI bisa dibilang cukup rendah jumlah penontonnya dan kebanyakan masyarakat mengira TVRI sudah hilang masa kejayaannya seperti dahulu kala.

Sungguh disayangkan mengingat TVRI merupakan salah satu stasiun TV terbesar di Indonesia, penurunan jumlah penonton yang sangat drastis mengakibatkan TVRI sudah sulit untuk mendapatkan kepercayaan penonton seperti sedia kala. Seiring berkembangnya stasiun TV lain membawa dampak buruk bagi TVRI mulai dari penurunan jumlah penonton sampai pendapatan yang di dapat TVRI mengalami penurunan dan menjadi banyak pertanyaan masyarakat tentang masa depan TVRI seperti apa.

Di tahun ini, TVRI sudah mulai melakukan pergerakan di bidang media sosial dalam rangka menaikan jumlah penonton lagi. Mulai dari Instagram, Youtube, Facebook. Contohnya dalam konten Youtube TVRI, setiap harinya menayangkan berbagai kejadian yang sedang terjadi atau menjadi trend dalam masyarakat, mulai dari berita olahraga sampai berita politik.

\section{Simpulan}

TVRI merupakan satu satunya stasiun TV milik negara yang masih beroperasi hingga sekarang, sempat hilang ketenarannya dan sekarang muncul lagi dengan sebuah inovasi baru dengan menambahkan divisi media sosial yang tentunya menjadi modal yang berharga mengingat sudah banyak stasiun TV lain yang sudah sejak lama membuatnya. Terlebih lagi masyarakat sudah lama sekali menginggalkan TVRI karena apa yang di siarkan tidak mengikuti trend perkembangan sekarang. Keadaan TVRI dalam industri penyiaran merupakan sebuah perjuangan yang sangat sulit, dikarenakan sudah banyak yang sudah beralih ke TV swasta lain dan TVRi masih tetap menjaga naik baiknya dengan masih memberikan masyarakat tentang program program acaranya yang padahal sudah tidak mengikuti trend perkembangan jaman.

\section{Ucapan Terima Kasih}

Puji dan syukur kepada Tuhan YME atas segala berkat dan rahmat-Nya sehingga peneliti dapat melaksanakan kegiatan penelitian dan menyelesaikan penulisan laporan akhir skripsi ini. Penyusunan skripsi ini dapat selesai karena bantuan dan dukungan dari banyak pihak. Oleh sebab itu, peneliti ingin menyampaikan rasa terima kasih yang sebesar-besarnya kepada semua pihak yang ikut terlibat dan telah membantu peneliti selama proses penelitian ini berlangsung yaitu: dan Bapak Andi Fachrudin selaku narasumber TVRI. Kepada Felia, Hansen Hindhartha dan Gilang Putra Ramadhan membantu penulis dalam menyelesaikan penelitian. Peneliti mengharapkan bahwa skripsi ini dapat menambah wawasan pihak lain. Di akhir kata penulis mengucapkan sekian dan terima kasih. 


\section{Daftar Pustaka}

Beranda TVRI. (n.d.). TVRI dari masa ke masa. April 10, 2019. http://tvri.go.id/about Dewi, Santi. (2018, Mei 7). Helmi Yahya : beri waktu 2 tahun agar TVRI kembali Berjaya. Maret 15 , 2019. Idntimes.http://lifestyle.okezone.com/read/2013/01/04/408/741602/kenalinegerisendiri-sebelum-jelajahi-negeri-orang-i

Kominfo. (November 11, 2013). Konvensi RSKKNI Produser TV. https://kominfo.go.id/index.php/content/detail/3464/Konvensi+RSKKNI+Produ ser+TV/0/berita_satker

Morissan. (2010). Komunikasi Pemasaran Terpadu, Prenadamedi Group

Yin, Robert K. (2013). desain dan metode, PT RajaGrafindo Persada 